\title{
RESEARCH ON SURFACE ROUGHNESS OF CIRCULAR ARC CUT BY ASJ
}

\author{
Fengchao Wang, Chuwen Guo, Wei Zhao, Li Zhu
}

Preliminary notes

Full factorial design of experiments was developed in order to investigate the effects of jet pressure, cutting feed, and circular arc radius upon the one response variable surface roughness of circular arc cut by abrasive suspension jet (ASJ). And orthogonal design of experiments was used for analysing the magnitude of effects of parameters on roughness of the cutting surface at different depths. Slowing down the traverse speed is the most effective method to reduce the surface roughness. In addition, comparing the topography of the cutting surface with that by AWJ, it is found that the surface also consists of four zones: initial zone, smooth zone, transition zone and rough zone. Finally, the multiple linear regression was employed to establish the model of cutting surface roughness at different depths, which was proved to be reliable by experiments. The conclusions can provide theoretical guidance for improving the cutting efficiency of ASJ.

Keywords: ASJ (abrasive suspension jet); circular arc cutting; roughness; surface topography

Istraživanje površinske hrapavosti kružnog luka rezanog mlazom abrazivne otopine

Prethodno priopćenje

Izrađen je potpuni faktorijalni plan eksperimenata za istraživanje učinaka tlaka mlaza, reznog posmaka i polumjera kružnog luka na površinsku hrapavost kružnog luka rezanog mlazom abrazivne otopine - abrasive suspension jet (ASJ). Ortogonalnim planom eksperimenata analizirala se veličina djelovanja parametara na hrapavost rezne površine na različitim dubinama. Smanjivanje brzine prijelaza je najučinkovitija metoda za smanjenje površinske hrapavosti. Uz to, usporedbom topografije rezne površine s onom pomoću AWJ, ustanovilo se da je površina sastavljena od četiri zone: inicijalna zona, glatka zona, prijelazna zona i gruba zona. Konačno, primijenjena je metoda multipne linearne regresije za postavljanje modela hrapavosti površine na različitim dubinama, što se eksperimentima potvrdilo kao pouzdano. Zaključci mogu poslužiti kao teorijski vodič za poboljšanje učinkovitosti rezanja pomoću ASJ.

Ključne riječi: hrapavost; mlaz abrazivne otopine (ASJ); rezanje kružnog luka; topografija površine

\section{Introduction}

Since the 70s when the first water jet cutting machine was invented [1], kinds of water jet machines have been used widely in modern industries. In the early time, pure water jet was just regarded as a flexible tool for cutting soft materials like plastic, paper and wood [2, 3]. However, the jet consisting of water and abrasives extends the range of cutting ability, and can be used for cutting most kinds of materials including metal and even diamond [4]. Due to the different ways of adding abrasives into the pure water jet, the abrasive jet was divided into abrasive water jet (AWJ) and abrasive suspension jet (ASJ). In AWJ system, water jet passes through a mixing chamber where low pressure was generated used for the pneumatic transport of abrasives. Then the jet re-enters the focusing tube where abrasives are accelerated by the water jet. However in ASJ system, high pressure water and abrasives are added into an abrasive suspension storage vessel at the same time. And then the abrasive suspension will be sprayed from the nozzle [5].

The periodic array of striation at the lower area of the AWJ cutting surface is closely related to the surface roughness. Hashish [6] proposed a simple physical model for describing the waviness phenomenon associated with AWJ cutting. And model predictions were consistent with the experimental surface waviness data under certain conditions. However, the model is not suitable for the cutting where the thickness of the material is less than or equal to the depth of the cutting wear zone $h_{c}$. The basic AWJ waviness model is expressed as:

$$
\frac{2 R_{w}}{d_{n}}=1-\sqrt{1-\left(\frac{\pi}{4}\right)^{2} \cdot\left(\frac{d_{n}\left(h-h_{c}\right) u}{0,5 m_{a} v_{j}^{2} / \varepsilon}\right)} .
$$

Roughness of the cutting surface is obviously associated with vibration of the AWJ system. Chao [7, 8] used the Fourier transform and carried out experiments to determine the characteristics of the cutting surface. And he finally concluded that the distinction between the various regions of the whole cutting surface is the uneven amplitude and the nozzle vibration strongly influences the waviness of the cutting surfaces. Moreover, he found that forced vibration of the mechanical structure had a significant impact on surface striations using the spectral analysis. Using the LabView 8.5 software to monitor and process the vibrations, Hreha [9] deals with the determination of vibration frequency depending on the impact of abrasive particles during cutting of materials. And he finally obtained the result that the on-line process control of the abrasive mass flow rate can optimize the vibration frequency for improving the quality of surface created by abrasive water jet. Moreover, cutting heterogeneous material consisting of stainless steel and alloy $\mathrm{AlCuMg}_{2}$ by abrasive water jet, Hreha [10] confirmed the hypothetical assumption about direct relation between surface quality and vibration emission. Also he took advantage of the vibration on detecting the malfunction of abrasive supplying and the focusing tube wear [11]. With the scanned vibration signal of material subjected to frequency analysis, the result was obtained that the shift of the amplitudes will decrease with the increase of the abrasive mass flow.

With many studies on surface topography of the processed material done by scholars, a lot of achievements have been scored. Chen [12] used a scanning electron microscope to investigate the characteristic of cutting surfaces and a non-invasive technique, Laser Doppler Anemometry to analyse the abrasive particle distribution 
in the jet. According to a series of experiments, he presented a conclusion that abrasive particle distribution in the jet can affect the striation formation. Krolczyk [13] conducted experiments to identify surface roughness in the dry machining of Duplex Stainless Steel coated with sintered carbide. Comparing the load curves and roughness profiles for various cutting wedges and variable cutting parameters, he drew the conclusion that dry cutting leads to a decrease in friction for lubricated surfaces, providing a small initial contact area where the surface is contacted. Wojciechowski [14] established a surface roughness height model including surface inclination angle, cutter's run out and minimum uncut chip thickness in the ball end milling of hardened steel. The result of analysis, surface inclination has significant influence on the generated surface texture, suggests that the appropriate selection of the surface inclination angle in the specified machining strategy can improve the surface quality.

Most of the present research on roughness of abrasive water jet cutting surface is aimed at the AWJ cutting and linear cutting. In this paper, the effects of jet pressure, traverse speed, and circular arc radius on surface roughness were investigated in circular arc cutting with ASJ. And orthogonal design of experiments was used for analyzing the magnitude of effects of parameters on roughness of the cutting surface at different depths. Moreover, the paper compared the topography of the cutting surface with that by AWJ. And one more significant work is establishing the roughness model, which can improve the material utilization and the cutting efficiency.

\section{Experimental setup}

For the research on the roughness of circular arc cutting surface, the JB-4C precision roughness step tester was used for measuring the roughness of the arc surface. The experimental material is 304 stainless steel, whose thickness is $8 \mathrm{~mm}$.

The paper aimed at the effects of processing parameters on roughness of circular arc cutting surface in ASJ cutting and three main processing parameters were considered as the influence factors, which included the jet pressure $\mathrm{P}$, the traverse speed $\mathrm{V}$ and the circular arc radius $\mathrm{R}$. The other processing parameters were consistent. The abrasive used was Garnet of grade 200 mesh, abrasive mixing rate was $330 \mathrm{~g} / \mathrm{min}$, nozzle diameter was $0,25 \mathrm{~mm}$ and stand-off distance was $5,38 \mathrm{~mm}$.

Table 1 Arc roughness experimental parameters

\begin{tabular}{|c|c|c|c|}
\hline Level & $\begin{array}{c}\text { Jet pressure } \\
P / \mathrm{MPa}\end{array}$ & $\begin{array}{c}\text { Traverse speed } \\
v / \mathrm{mm} / \mathrm{s}\end{array}$ & $\begin{array}{c}\text { Circular arc radius } \\
R / \mathrm{mm}\end{array}$ \\
\hline 1 & 45 & 0,2 & 4 \\
\hline 2 & 55 & 0,3 & 8 \\
\hline 3 & 65 & 0,4 & 12 \\
\hline 4 & - & - & 16 \\
\hline
\end{tabular}

The experiment was divided into two parts: The full factorial design $(3 \times 3 \times 4=36$ tests $)$ was used for determining the effects of different processing parameters on the surface roughness. And the detail of the levels for parameters is shown in Tab. 1. The other part of experiment adopted the orthogonal experimental method. Tab. 2 is the orthogonal experiment table of L9 $\left(3^{4}\right)$.

Table 2 Orthogonal experiment table of L9 $\left(3^{4}\right)$

\begin{tabular}{|c|c|c|c|}
\hline Number & $\begin{array}{c}\text { Jet pressure } \\
P / \mathrm{MPa}\end{array}$ & $\begin{array}{c}\text { Traverse speed } \\
v / \mathrm{mm} / \mathrm{s}\end{array}$ & $\begin{array}{c}\text { Circular arc radius } \\
R / \mathrm{mm}\end{array}$ \\
\hline 1 & 45 & 0.2 & 8 \\
\hline 2 & 45 & 0.4 & 12 \\
\hline 3 & 45 & 0.6 & 16 \\
\hline 4 & 55 & 0.2 & 12 \\
\hline 5 & 55 & 0.4 & 16 \\
\hline 6 & 55 & 0.6 & 16 \\
\hline 7 & 65 & 0.2 & 8 \\
\hline 8 & 65 & 0.4 & 12 \\
\hline 9 & 65 & 0.6 & \\
\hline
\end{tabular}

\section{Results and discussion}

\subsection{Effects of the parameters on roughness}

In this section, the experiment data of the full factorial designed part have been sorted out and drawn into linear graphs by commercial statistical software MATLAB. And the data of surface roughness were measured from the convexity of circular arc cutting surface. The effects of the different processing parameters on surface roughness can be shown in the linear graph clearly. Then the paper presented the reasons that the different processing parameters can affect the surface roughness combined with the theoretical knowledge.

It is well known that increasing jet pressure and slowing down traverse speed can lead to a smoother section in AWJ cutting. Although the experiment is ASJ circular arc cutting, the same result was obtained. The paper put emphasis on effect of the circular arc radius on roughness of the cutting surface.

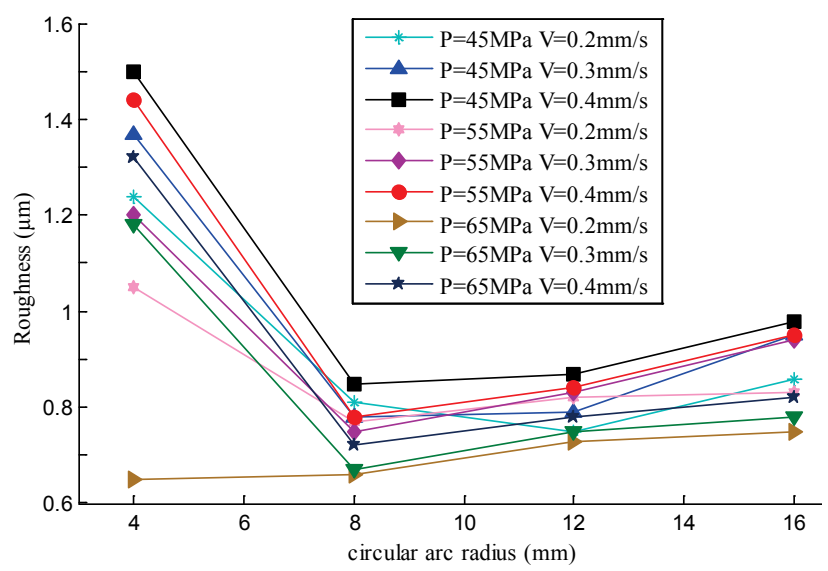

Figure 1 Effect of radius on roughness of cutting surface

As shown in Fig. 1, the surface roughness descends sharply at first then increases gently with the circular arc radius increasing. But a set of experiment data $(P=65$ $\mathrm{MPa}, v=0,2 \mathrm{~mm})$ is not in conformity with the conclusion, whose trend is that the surface roughness always increases gently with the arc radius increasing. This will be discussed in details below.

Fig. 2 describes the path of nozzle in circular arc cutting. The velocity of the centre point of jet is $v_{0}$, which is equal to the traverse speed $\mathrm{v}$. The angular velocity of circular arc cutting is $\omega$. And the diameter of the jet reaching the cutting surface is $d$. According to the 
geometric model the traverse speed of jet at the convexity of circular arc cutting surface can be worked out.

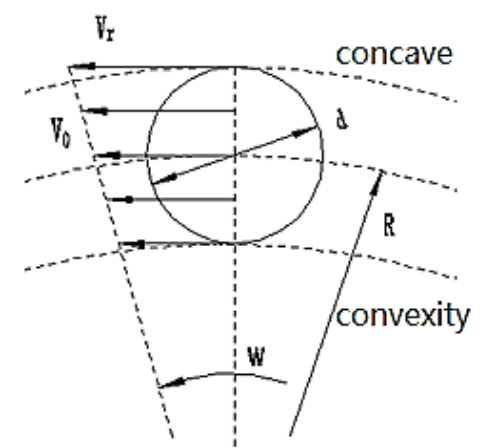

Figure 2 Velocity distribution

$v_{c}=w \times r=\left(1-\frac{d}{2 R}\right) v$.

Based on the formula (1), when larger radius circular arc cutting is proceeded, the traverse speed of jet at the convexity becomes faster, which can cause the increasing of the surface roughness. In the experiment and even in the practice the circular arc radius $R$ is much larger than the diameter of the jet reaching the cutting surface $d$. Then with the circular arc radius increasing, the traverse speed of jet at the convexity becomes a little faster, which causes the surface roughness to increase gently.

The above theory can be used to explain the surface roughness gently increases with $R$ ranging from $8 \mathrm{~mm}$ to $16 \mathrm{~mm}$. But the phenomenon that the surface roughness sharply increases with $R$ reducing to $4 \mathrm{~mm}$ does not conform to the theory. The experimental result $(P=65$ $\mathrm{MPa}, v=0,2 \mathrm{~mm})$ is an exception, which is consistent with the theory when $R$ ranges from $4 \mathrm{~mm}$ to $16 \mathrm{~mm}$. In view of the experiment $(P=65 \mathrm{MPa}, v=0,2 \mathrm{~mm})$ owning the most powerful cutting ability, the critical cutting energy of jet $E_{0}$ corresponding to each circular arc radius is presented. If the actual jet energy $E$ cannot reach $E_{0}$, the roughness of the cutting surface will increase sharply. The reason is that most of the jet energy is used for longitudinal cutting and the left will not satisfy the lateral polishing.

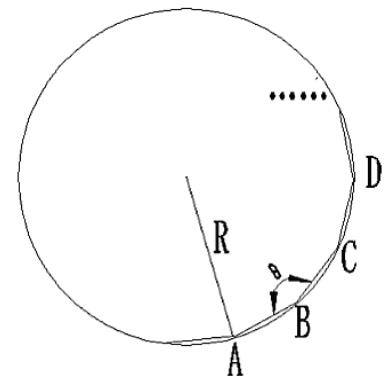

Figure 3 Trajectory of circular interpolation

The path of the machine tool can be used to analyse what is the critical cutting energy $E_{0}$. On account of the circular interpolation, double-axis cooperation control $\mathrm{CNC}$ machine tool for circular arc cutting runs in many line segments of interpolation (Fig. 3). And the cycle of interpolation is marked as $I_{\text {nsert }}$, whose unit is millisecond.

The length of each line segment:
$\Delta L=\frac{v \times I_{\text {nsert }}}{1000}=A B=B C=\cdots$.

Due to the short cycle of interpolation, the sum of length of the line segments is approximately equal to the perimeter of circular.

$n \times \Delta L \approx 2 \pi R$

The geometric figure composed of the line segments can be regarded as inscribed polygon of circle, for which the angle of two adjacent line segments $\theta$ will be figured out.

$\theta=\frac{2 \pi(n-2)}{n}=2 \pi\left(1-\frac{v \times I_{\text {nsert }}}{\pi R \times 1000}\right)$

In fact a series of convex corners are formed on the surface in circular arc cutting. And based on the formula (4), minor radius circular arc cutting can lead to small convex angle, which will result in the increase of the surface roughness. So that $E_{0}$ corresponding to each circular arc radius is the minimum jet energy to eliminate the increase of roughness caused by the convex angle.

In conclusion, there are two kinds of roughness trend along with the decrease of the radius in circular arc cutting. On one hand $\left(E<E_{0}\right)$, the convex corners of interpolation is the determinant, for which the surface roughness increases sharply with the circular arc radius decreasing. On the other hand $\left(E>E_{0}\right)$, the velocity distribution of the jet at cutting area determines that the surface roughness decreases gently with the circular arc radius decreasing. In the present experiments, when $R$ reduces to $4 \mathrm{~mm}$, the actual jet energy $E$ will be less than the critical cutting energy $E_{0}$ except the experiment $(P=$ $65 \mathrm{MPa}, v=0,2 \mathrm{~mm})$.

\subsection{Analysis of variance}

For studying the magnitude of effects of parameters on roughness of the cutting surface at various depths, the experimental data of the orthogonal designed part have been sorted out and analysed using analysis of variance. The data of surface roughness were measured on the three lines of the cutting surface at various depths. And each data is the average of multiple measurement results.

\subsubsection{Roughness analysis of the upper cutting surface}

Tab. 3 lists the roughness data of the upper cutting surface in the orthogonal designed experiment, which were sorted out by means of range analysis shown in Tab. 4. According to the result of range analysis, effects of parameters on the surface roughness at the upper area are ranked in the order of traverse speed, jet pressure, systemic error and circular arc radius. Thus in the process of practical production, slowing the traverse speed down is the most effective way to reduce the surface roughness at the upper area. And the effect of circular arc radius on 
surface roughness is lower than systemic error, which can be ignored.

Table 3 Roughness data of the upper cutting surface

\begin{tabular}{|c|c|c|c|c|c|}
\hline Number & 1 & 2 & 3 & 4 & 5 \\
\hline$R a$ & 1,125 & 1,044 & 1,853 & 0,825 & 0,908 \\
\hline Number & 6 & 7 & 8 & 9 & - \\
\hline$R a$ & 1,347 & 0,851 & 0,846 & 1,674 & - \\
\hline
\end{tabular}

Table 4 Roughness range table of the upper cutting surface

\begin{tabular}{|c|c|c|c|c|}
\hline Level & $P$ & $V$ & $R$ & Error \\
\hline K1 & 1,341 & 0,934 & 1,106 & 1,236 \\
\hline K2 & 1,027 & 0,933 & 1,181 & 1,081 \\
\hline K3 & 1,124 & 1,625 & 1,204 & 1,175 \\
\hline Range & 0,314 & 0,692 & 0,098 & 0,155 \\
\hline
\end{tabular}

Tab. 5 shows the result of variance analysis of the experimental data on the significant level $\alpha$ adopting 0,05 . Effects of parameters on the surface roughness at the upper area are ranked in the order of traverse speed, jet pressure, systemic error and circular arc radius, which is consistent with the conclusion range analysis. And only the traverse speed has a significant effect on the roughness of the upper cutting surface.

Table 5 Roughness variance analysis of the upper cutting surface

\begin{tabular}{|c|c|c|c|c|}
\hline Parameters & DEVSQ & F-ratio & F threshold & Significance \\
\hline$P$ & 0,155 & 4,189 & 19,000 & - \\
\hline$V$ & 0,956 & 25,838 & 19,000 & $*$ \\
\hline$R$ & 0,016 & 0,432 & 19,000 & - \\
\hline Error & 0,04 & - & - & - \\
\hline
\end{tabular}

\subsubsection{Roughness analysis of the middle cutting surface}

Tab.6 lists the roughness data of the middle cutting surface in the orthogonal designed experiment, which were sorted out by means of range analysis shown in Tab. 7. According to the result of range analysis, effects of parameters on the surface roughness at the middle area are ranked in the order of traverse speed, systemic error, circular arc radius and jet pressure. Thus in the process of practical production, slowing the traverse speed down is also the most effective way to reduce the surface roughness at the middle area. And the effects of circular arc radius and jet pressure on surface roughness are lower than systemic error, which can be ignored.

Table 6 Roughness data of the middle cutting surface

\begin{tabular}{|c|c|c|c|c|c|}
\hline Number & 1 & 2 & 3 & 4 & 5 \\
\hline$R a$ & 0,682 & 0,797 & 1,483 & 0,817 & 0,833 \\
\hline Number & 6 & 7 & 8 & 9 & - \\
\hline$R a$ & 1,032 & 0,756 & 0,871 & 1,355 & - \\
\hline
\end{tabular}

Table 7 Roughness range table of the middle cutting surface

\begin{tabular}{|c|c|c|c|c|}
\hline Level & $P$ & $V$ & $R$ & Error \\
\hline K1 & 0,987 & 0,752 & 0,862 & 0,957 \\
\hline K2 & 0,894 & 0,834 & 0,990 & 0,862 \\
\hline K3 & 0,994 & 1,290 & 1,024 & 1,057 \\
\hline Range & 0,100 & 0,538 & 0,162 & 0,195 \\
\hline
\end{tabular}

Tab. 8 shows the result of variance analysis of the experimental data on the significant level $\alpha$ adopting 0,05 . Effects of parameters on the surface roughness at the middle area are ranked in the order of traverse speed, systemic error, circular arc radius and jet pressure, which is consistent with the range analysis conclusion. However none of parameters has a significant effect on the roughness of the middle cutting surface.

Table 8 Roughness variance analysis of the middle cutting surface

\begin{tabular}{|c|c|c|c|c|}
\hline Parameters & DEVSQ & F-ratio & F threshold & Significance \\
\hline$P$ & 0,019 & 0,333 & 19,000 & - \\
\hline$V$ & 0,505 & 8,860 & 19,000 & - \\
\hline$R$ & 0,044 & 0,772 & 19,000 & - \\
\hline Error & 0,060 & - & - & - \\
\hline
\end{tabular}

\subsubsection{Roughness analysis of the lower cutting surface}

Tab. 9 lists the roughness data of the lower cutting surface in the orthogonal designed experiment, which were sorted out by means of range analysis shown in Tab. 10. According to the result of range analysis, effects of parameters on the surface roughness at the lower area are ranked in the order of traverse speed, circular arc radius, jet pressure and systemic error. Thus in the process of practical production, slowing the traverse speed down is the most effective way to reduce the surface roughness at the lower area.

Table 9 Roughness data of the lower cutting surface

\begin{tabular}{|c|c|c|c|c|c|}
\hline Number & 1 & 2 & 3 & 4 & 5 \\
\hline$R a$ & 0,883 & 0,751 & 1,745 & 0,863 & 1,124 \\
\hline Number & 6 & 7 & 8 & 9 & - \\
\hline$R a$ & 1,466 & 0,808 & 0,657 & 1,482 & - \\
\hline
\end{tabular}

Table 10 Roughness range table of the lower cutting surface

\begin{tabular}{|c|c|c|c|c|}
\hline Level & $P$ & $V$ & $R$ & Error \\
\hline K1 & 1,126 & 0,851 & 1,002 & 1,163 \\
\hline K2 & 1,151 & 0,844 & 1,032 & 1,008 \\
\hline K3 & 0,982 & 1,564 & 1,226 & 1,088 \\
\hline Range & 0,169 & 0,720 & 0,224 & 0,155 \\
\hline
\end{tabular}

Table 11 Roughness variance analysis of the lower cutting surface

\begin{tabular}{|c|c|c|c|c|}
\hline Parameters & DEVSQ & F-ratio & F threshold & Significance \\
\hline$P$ & 0,050 & 1,389 & 19,000 & - \\
\hline$V$ & 1,027 & 28,528 & 19,000 & $*$ \\
\hline$R$ & 0,088 & 2,444 & 19,000 & - \\
\hline Error & 0,04 & - & - & - \\
\hline
\end{tabular}

Tab. 11 shows the result of variance analysis of the experimental data on the significant level $\alpha$ adopting 0,05 . Effects of parameters on the surface roughness at the lower area are ranked in the order of traverse speed, circular arc radius, jet pressure and systemic error, which is consistent with the conclusion range analysis. And only the traverse speed has a significant effect on the roughness of the lower cutting surface.

\subsection{Comparison of surface topography with AWJ}

As shown in Fig. 4, roughness data of the nine orthogonal designed experiments were sorted out and drawn into linear graph. Under the same experimental conditions, the roughness descends at first then increases with the depth of the cutting surface increasing except the No. 2 experiment $(P=45 \mathrm{MPa}, V=0,4 \mathrm{~mm} / \mathrm{s}, R=12$ $\mathrm{mm})$ and No. 8 experiment $(P=65 \mathrm{MPa}, V=0,4 \mathrm{~mm} / \mathrm{s}, R$ $=8 \mathrm{~mm})$. But considering the systemic error and the measuring error, they do not affect the validity of the conclusion. 


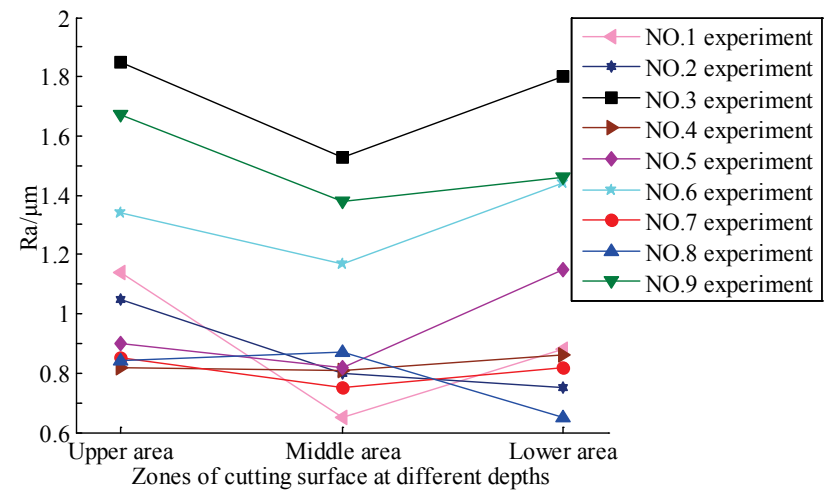

Figure 4 Roughness of the cutting surface at different depths

In the study of AWJ cutting, Hloch [15] put forward the initial zone at the upper area of the cutting surface, where the roughness is larger than the Smooth zone. Fig. 5 is the roughness partition of abrasive water jet cutting surface.

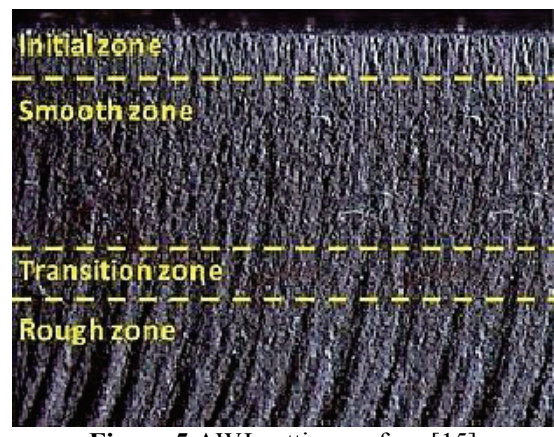

Figure 5 AWJ cutting surface [15]

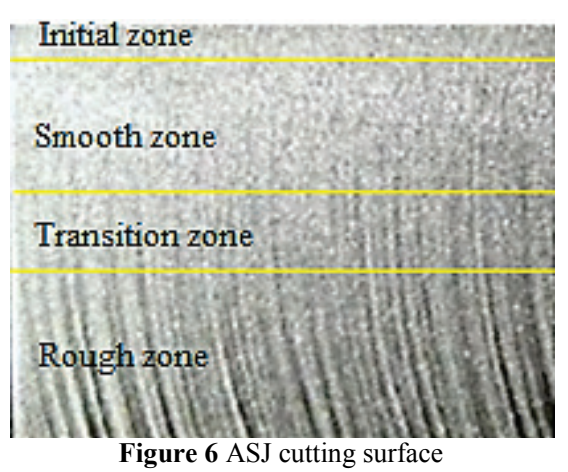

In the present experiments roughness of the upper cutting surface is larger than the middle cutting surface, which can prove that the ASJ cutting surface also has the initial zone. Thus as shown in Fig. 6, the ASJ cutting surface was divided into 4 areas: initial zone, smooth zone, transition zone and rough zone. Because the upper measurement point on the cutting surface is in the initial zone certainly, the depth of initial zone ranges from $2 \mathrm{~mm}$ to $4 \mathrm{~mm}$ in the experiments.

\subsection{Circular arc surface roughness model}

In order to improve the material utilization and the cutting efficiency, the paper quantified the influence of various factors on the roughness and established the roughness model of the cutting surface at different depths based on multiple linear regression. Considering the effect of the circular arc radius on roughness, the paper presented the following model.

$$
R a=K P^{c_{1}} H^{c_{2}} v^{c_{3}} d_{f}^{c_{4}} R^{c_{5}}
$$

where: $K$ - coefficient (related with abrasives and material); $H$ - thickness of material; $d_{f}$ - nozzle diameter; $c_{1}, c_{2}, c_{3}, c_{4}, c_{5}$ - undetermined coefficient.

Due to the fixed value of the material thickness and nozzle diameter, the above formula can be simplified.

$$
R a=K P^{c_{1}} v^{c_{2}} R^{c_{3}}
$$

Log algorithm can be used in the formula (6).

$L_{n} R a=L_{n} K+c_{1} L_{n} P+c_{2} L_{n} v+c_{3} L_{n} R$

Order:

$$
\begin{aligned}
& y=L_{n} R a, x_{1}=L_{n} P, x_{2}=L_{n} v, x_{3}=L_{n} R, c_{0}=L_{n} K . \\
& y_{i}=c_{0}+c_{1} x_{i 1}+c_{2} x_{i 2}+c_{3} x_{i 3}
\end{aligned}
$$

Order:

$$
y=\left[\begin{array}{l}
y_{1} \\
y_{2} \\
\cdots \\
y_{9}
\end{array}\right]_{9 \times 1}, c=\left[\begin{array}{c}
c_{0} \\
c_{1} \\
\ldots \\
c_{3}
\end{array}\right]_{4 \times 1}, x=\left[\begin{array}{cccc}
1 & x_{11} & x_{12} & x_{13} \\
1 & x_{21} & x_{22} & x_{23} \\
1 & \ldots & \ldots & \ldots \\
1 & x_{91} & x_{92} & x_{93}
\end{array}\right]_{9 \times 4} .
$$
form.

Linear regression model can be expressed as matrix

$$
y_{9 \times 1}=c_{4 \times 1} x_{9 \times 4} .
$$

Considering the random error $\varepsilon(E(\varepsilon)=0)$, least square method is used to solve the undetermined coefficients, by which the paper can obtain the final regression equation and even the roughness model of the ASJ circular arc cutting surface at different depths.

The final regression equation:

$y=c_{0}^{\prime}+c_{1}^{\prime} x_{i 1}+c_{2}^{\prime} x_{i 2}+c_{3}^{\prime} x_{i 3}+\varepsilon$

And the final roughness model:

$R a=K P^{c^{\prime} 1} v^{c^{\prime} 2} R^{c^{\prime} 3}$

\subsubsection{Roughness models}

According to the characteristic of the ASJ cutting surface that the roughness changes obviously at different depths, three roughness models were established for corresponding to three zones (upper area, middle area and lower area) of the cutting surface. The experimental data was used for regression analysis by MATLAB. And Tab. 12 shows the result of multiple linear regression. 


\begin{tabular}{|c|c|c|c|c|c|c|}
\hline \multirow{2}{*}{ Coefficient } & \multicolumn{2}{|c|}{ Upper area } & \multicolumn{2}{|c|}{ Middle area } & \multicolumn{2}{|c|}{ Lower area } \\
\hline & Value & Confidence interval & Value & Confidence interval & Value & Confidence interval \\
\hline$c_{0}^{\prime}$ & 2,668 & {$[-3,23 ; 8,567]$} & $-0,458$ & {$[-4.78 ; 3.86]$} & 1.127 & {$[-5.99 ; 8.24]$} \\
\hline$c_{1}^{\prime}$ & $-0,560$ & {$[-1,96 ; 0,84]$} & 0,081 & {$[-0,94 ; 1,11]$} & $-0,327$ & {$[-2,01 ; 1,36]$} \\
\hline$c_{2}^{\prime}$ & 0,452 & {$[-0,01 ; 0,92]$} & 0,448 & {$[0,11 ; 0,79]$} & 0,487 & {$[-0,07 ; 1,05]$} \\
\hline$c_{3}^{\prime}$ & 0,056 & {$[-0,68 ; 0,80]$} & 0,209 & {$[-0,33 ; 0,75]$} & 0,286 & {$[-0,61 ; 1,18]$} \\
\hline- & \multicolumn{2}{|c|}{$r^{2}=0,60 ; F=2,46 ; P=0,18$} & \multicolumn{2}{|c|}{$r^{2}=0,71 ; F=4,17 ; P=0,08$} & \multicolumn{2}{|c|}{$r^{2}=0,54 ; F=1,98 ; P=0,24$} \\
\hline Equation & \multicolumn{2}{|c|}{$y=2,668-0,56 x_{1}+0,452 x_{2}+0,056 x_{3}$} & \multicolumn{2}{|c|}{$y=-0,458+0,081 x_{1}+0,448 x_{2}+0,209 x_{3}$} & \multicolumn{2}{|c|}{$y=1,127-0,327 x_{1}+0,487 x_{2}+0,286 x$} \\
\hline
\end{tabular}
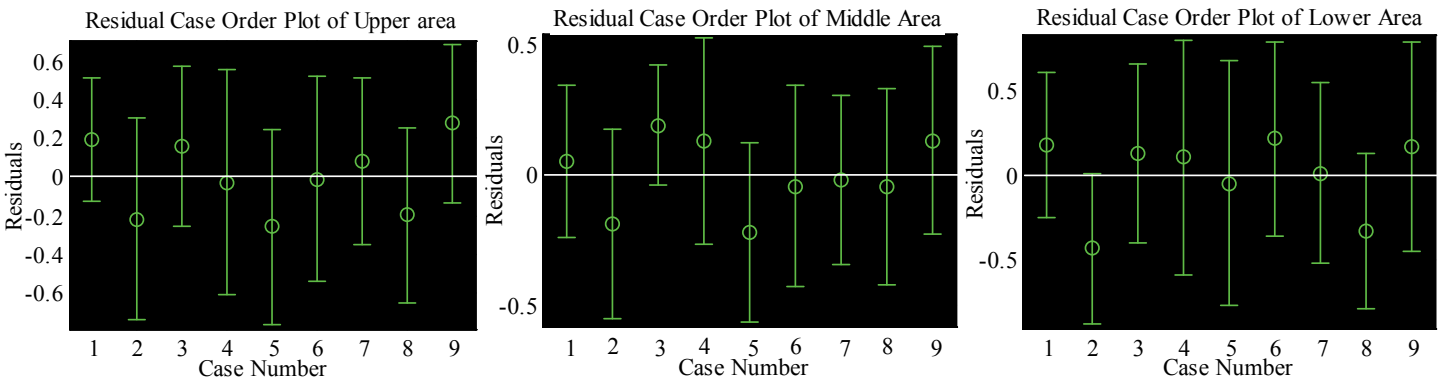

Figure 7 Residual case order plot

As shown in residual case order plot (Fig. 7), zero is included in all of the confidence intervals of the residuals, which indicates that the above regress equations can accord with the original date. Thus the paper deduced the three roughness models.

The roughness model of upper area:

$$
R a=14,405 P^{-0,56} v^{0,452} R^{0,056} .
$$

The roughness model of middle area:

$$
R a=0,632 P^{0,081} v^{0,448} R^{0,209} .
$$

The roughness model of lower area:

$$
R a=3,087 P^{-0,327} v^{0,487} R^{0,286} .
$$

\subsubsection{Accuracy of roughness models}

For verifying the accuracy of the three roughness models, the paper carried out a serious of ASJ circular arc cutting experiments under 9 groups of conditions. And Tab. 13 shows the conditions of the experiment.

As shown in Tab. 14, the absolute error $E a$ is equal to the absolute value of the difference between the experimental measured value $\xi^{\prime}$ and the predicted value $\xi$. Contrasting with the American standard roughness form, the measured roughness values are involved in the range from $0,63 \mu \mathrm{m}$ to $1,6 \mu \mathrm{m}$. And the average value of absolute error is $0,048 \mu \mathrm{m}$ except $0,407 \mu \mathrm{m}$ (identified as abnormal data) in the No. 9 experiment. Thus the error of the roughness models almost does not affect the grading of the cutting surface's roughness, which can prove that the roughness models are reliable in practice.

Table 13 Conditions of the verify experiment

\begin{tabular}{|l|c|c|c|c|c|c|c|c|c|}
\hline \multicolumn{1}{|c|}{ Number } & 1 & 2 & 3 & 4 & 5 & 6 & 7 & 8 & 9 \\
\hline Jet pressure (MPa) & 46 & 48 & 50 & 52 & 54 & 56 & 58 & 60 & 62 \\
\hline Traverse speed (mm/s) & 0,2 & 0,3 & 0,6 & 0,4 & 0,5 & 0,2 & 0,5 & 0,4 & 0,3 \\
\hline Radius (mm) & 8 & 9 & 10 & 11 & 9 & 14 & 15 & 13 & 12 \\
\hline
\end{tabular}

Table 14 Absolute error of the roughness models

\begin{tabular}{|c|c|c|c|c|c|c|c|c|c|}
\hline \multirow{2}{*}{ No. } & \multicolumn{3}{|c|}{ The upper area } & \multicolumn{3}{c|}{ The middle area } & \multicolumn{3}{c|}{ The lower area } \\
\cline { 2 - 11 } & $\xi^{\prime}$ & $\xi$ & $E a$ & $\xi^{\prime}$ & $\xi$ & $E a$ & $\xi^{\prime}$ & $\xi$ & $E a$ \\
\hline 1 & 0,843 & 0,916 & 0,073 & 0,651 & 0,648 & 0,003 & 0,700 & 0,732 & 0,032 \\
\hline 2 & 1,032 & 1,081 & 0,049 & 0,743 & 0,800 & 0,057 & 0,990 & 0,900 & 0,090 \\
\hline 3 & 1,501 & 1,453 & 0,048 & 1,124 & 1,119 & 0,005 & 1,369 & 1,296 & 0,073 \\
\hline 4 & 1,162 & 1,190 & 0,028 & 0,912 & 0,955 & 0,043 & 1,010 & 1,079 & 0,069 \\
\hline 5 & 1,173 & 1,274 & 0,101 & 0,952 & 1,015 & 0,063 & 1,173 & 1,122 & 0,051 \\
\hline 6 & 0,812 & 0,846 & 0,034 & 0,801 & 0,740 & 0,061 & 0,764 & 0,806 & 0,042 \\
\hline 7 & 1,252 & 1,260 & 0,008 & 1,095 & 1,136 & 0,041 & 1,354 & 1,269 & 0,085 \\
\hline 8 & 1,182 & 1,109 & 0,073 & 1,056 & 1,003 & 0,053 & 1,050 & 1,080 & 0,030 \\
\hline 9 & 0,966 & 0,952 & 0,014 & 0,460 & 0,867 & 0,407 & 0,884 & 0,908 & 0,024 \\
\hline
\end{tabular}

\section{Conclusion}

The paper studied the effects of processing parameters on roughness of ASJ circular arc cutting surface using the full factorial design, and the reasons of circular arc radius affecting roughness was analysed emphatically. Then detailed conclusions were obtained.

(1) Due to the influence of convex corners of interpolation and velocity distribution of the jet at cutting area, the surface roughness descends sharply 
at first then increases gently with the circular arc radius increasing.

(2) The traverse speed is the most significant parameter on the surface roughness in ASJ circular arc cutting, and the jet pressure and circular arc radius are secondary factors.

(3) Similar with topography of the surface cut by AWJ, the topography of the surface cut by ASJ also involved four zones: initial zone, smooth zone, transition zone and rough zone.

(4) Three roughness models, which can improve the material utilization and the cutting efficiency, have been established and proved to be correct. The basic models of cutting surface roughness at different depths are:

The upper area: $R a=14,405 P^{-0,56} v^{0,452} R^{0,056}$.

The middle area: $R a=0,632 P^{0,081} v^{0,448} R^{0,209}$.

The lower area: $R a=3,087 P^{-0,327} v^{0,487} R^{0,286}$.

\section{Acknowledgements}

The authors gratefully acknowledge the Fundamental Research Funds for the Central Universities (2012LWB15) and the Natural Science Foundation of Jiangsu Province (BK20151147) for their financial supports.

\section{References}

[1] Walstad, O. M.; Noecker, P. W. Development of high pressure pumps and associated equipment for fluid jet cutting. // Proceedings of the first International Symposium on Jet Cutting Technology / Coventry, 1972.

[2] Brandt, S.; Louis, H.; Milchers, W.; Mohamed, M. Abrasive water jets - A multifunctional tool for advanced materials. // $7^{\text {th }}$ European Conference on Advanced Materials and Processes EuroMat, 2001

[3] Malone, D. E.; Friedrich, W. E.; Spooner, N. R.; Lim, P. P. K Knowledge based control in the processing of highly varying products. // Proceedings - IEEE International Conference on Robotics and Automation / San Diego, 1994, pp. 2903-2908. DOI: 10.1109/robot.1994.350898

[4] Axinte, D. A.; Srinivasu, D. S.; Kong, M. C.; Butler-Smith, P.W. Abrasive waterjet cutting of polycrystalline diamond: A preliminary investigation. // International Journal Advanced Manufacturing Technology. 49, 10(2009), pp. 797-803. DOI 10.1016/j.jimachtools.2009.04.003

[5] Louis, H.; Pude, F.; Von, R. C.; Versemann, R. Abrasive water suspension jet technology - Fundamentals, application and developments. // Rivista Italiana della Saldatura, 59, 6(2007), pp. 853-859. DOI: 10.1007/bf03266595

[6] Hashish, M. On the modelling of surface waviness produced by abrasive-waterjets. // $11^{\text {th }}$ International Symposium on Jet Cutting Technology / St Andrews, 1992, pp. 17-34. DOI 10.1007/978-94-011-2678-6_2

[7] Chao, J.; Geskin, E. S.; Chung, Y. Investigation of the dynamics of the surfaces topography formation during abrasive waterjet machining. // $11^{\text {th }}$ International Symposium on Jet Cutting Technology / St Andrews, 1992 , pp. 593-603. DOI: 10.1007/978-94-011-2678-6_39

[8] Chao, J.; Zhou, G.; Leu, M. C.; Geskin, E. Characteristics of abrasive waterjet generated surfaces and effects of cutting parameters and structure vibration. // Transaction of the ASME. 117, 4(1995), pp. 236-239. DOI: 10.1115/1.2803529

[9] Hreha, P.; Radvanská, A.; Hloch, S.; Peržel, V.; Królczyk, G.; Monková, K. Determination of vibration frequency depending on abrasive mass flow rate during abrasive water jet cutting. // International Journal of Advanced Manufacturing Technology. 77, 1-4(2014), pp. 763-774.

[10] Hreha, P.; Hloch, S.; Monka, P.; Monková, K.; Knapčíková, L.; Hlaváček, P.; Zeleňák, M.; Samardžić, I.; Kozak, D. Investigation of sandwich material surface created by abrasive water jet (AWJ) via vibration emission. // Metalurgija. 53, 1(2014), pp. 29-32.

[11] Hreha, P.; Radvanská, A.; Cárach, J.; Lehocká, D.; Monková, K.; Krolczyk, G.; Ruggiero, A.; Samardžić, I.; Kozak, D.; Hloch, S. Monitoring of focusing tube wear during abrasive waterjet (AWJ) cutting of AISI 309. // Metalurgija. 53, 4(2014), pp. 533-536.

[12] Chen, F. L.; Siores, E. The effect of cutting jet variation on surface striation formation in abrasive water jet cutting. // Materials Processing Technology. 135, 1(2003), pp. 1-5. DOI: 10.1016/S0924-0136(01)00579-9

[13] Krolczyk G. M.; Legutko S. Experimental analysis by measurement of surface roughness variations in turning process of duplex stainless steel. // Metrology and Measurement Systems. 21, 4(2014), pp. 759-770. DOl: 10.2478/mms-2014-0060

[14] Wojciechowski， S.; Twardowski， P.; Wieczorowski， M. Surface texture analysis after ball end milling with various surface inclination of hardened steel. // Metrology and Measurement Systems. 21, 1(2014), pp. 145-156. DOl: 10.2478/mms-2014-0014

[15] Hloch, S.; Valícek, J. Topographical anomaly on surfacescreated by abrasive waterjet. // International Journal Advanced Manufacturing Technology. 59, 5-8(2012), pp. 593-604.

\section{Authors' addresses}

\section{Fengchao Wang, doctor}

School of Electric Power Engineering, China University of Mining and Technology, Xuzhou, Jiangsu, 221116, China E-mail:wfc0317@163.com

Chuwen Guo, professor (corresponding author) School of Electric Power Engineering, China University of Mining and Technology, Xuzhou, Jiangsu, 221116, China E-mail: cwguo@cumt.edu.cn Tel. +86-516-83592200

\section{Wei Zhao, doctor}

1) School of Electric Power Engineering, China University of Mining and Technology, Xuzhou, Jiangsu, 221116, China 2) School of Mechanical and Power Engineering, North University of China, Taiyuan, 030051, China

E-mail: zhaowei_cumt@126.com

Zhu Li,

School of Electric Power Engineering, China University of Mining and Technology, Xuzhou, Jiangsu, 221116, China 